\title{
Douleur et aspects médicolégaux
}

\section{DOULEUR ET ASPECTS MÉDICO-LÉGAUX}

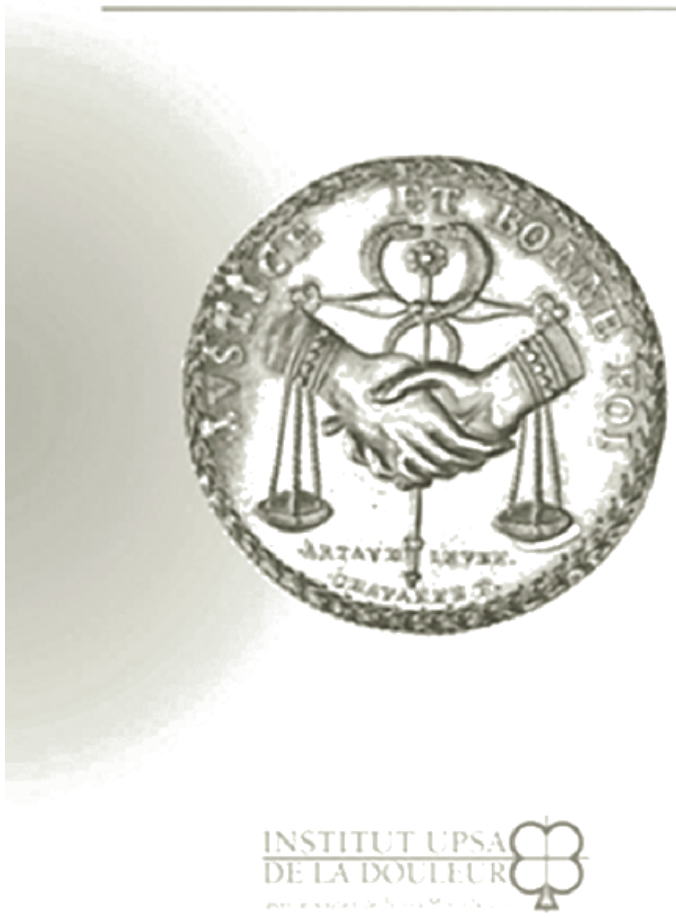

Pour cet ouvrage très fonctionnel, l'institut UPSA de la douleur a fait appel à des spécialistes tant du domaine de la santé que de celui du droit.

Le $D r$ Alain Serrie en a rédigé l'introduction pour en mettre le sujet en perspective.

Nathalie Lelièvre brosse un tableau synthétique et pratique des règles juridiques relatives aux professionnels de la prise en charge de la douleur ainsi que de la mission du médecin expert dans une action judiciaire.

Le Dr Frédéric Aubrun développe la place du protocole dans la prise en charge de la douleur, en particulier sous son aspect médicolégal.
Par ailleurs, quelle est la mission du médecin face au patient douloureux et à l'arrêt maladie ? Le Dr Jacqueline Cardona répond à cette question à laquelle les médecins sont souvent confrontés.

Enfin, Céline Avengozar et Gilles Barbier proposent des solutions de réinsertion professionnelle et sociale face au handicap et à la douleur.

Cet ouvrage est disponible sur le site Internet de l'institut: www.institut-upsa-douleur.org

Conflit d'intérêt : aucun. 